\title{
A hegemonia científica e o senso comum na internet: uma análise segundo a Epistemologia do Sul de Boaventura de Sousa Santos
}

\author{
Cleber Femina \& Kênia Maia \\ Universidade Federal do Rio Grande do Norte \\ E-mail: keniamaialyahoo.com
}

\begin{abstract}
Resumo
As concepções de Boaventura de Sousa Santos $(1995 ; 2010)$ sobre o atual cenário epistemológico nos orientam para compreender o relacionamento entre o conhecimento científico e o senso comum. Partindo do seu pensamento, principalmente no que tange à necessidade de uma ruptura com o modelo vigente, hegemônico e totalizante, para que a ciência expanda suas fronteiras e reconheça como válidas outras formas de saber, analisa-

mos os discursos envolvidos em um debate acerca dessa relação em um blog na internet. De acordo com as ideias de Michel Foucault (1999) e Eni Orlandi (2012) vimos que o pensamento científico moderno ainda exerce hegemonia sobre os demais saberes, porém o espaço virtual da internet permite um combate e pode ser utilizado como meio para o exercício da epistemologia proposta por Santos.
\end{abstract}

Palavras-chaves: Epistemologias do Sul; Ciência; Senso Comum; Internet.

\begin{abstract}
The conceptions of Boaventura de Sousa Santos $(1995 ;$ 2010) on the current epistemological setting guide us to understand the relationship between scientific knowledge and common sense. Starting from his thinking, especially with regard to the need of a rupture with the current model, hegemonic and to-

talizing, for science to expand its borders and recognize as valid other ways of knowing, we analyzed the speeches involved in a debate about that relationship in a blog on the internet. According to Michel Foucault (1999) and Eni Orlandi's (2012) ideas we saw that modern scientific thought still exerts hege-
\end{abstract}

Estudos em Comunicação no 21, 75-91 
mony over other forms of knowledge, but the virtual space of the internet allows to fight back, and can be used as a mean for the exercise of epistemology advocated by Santos.

Keywords: Southern Epistemologies; Science; Common sense; Internet.

\section{Introdução}

A relação entre o conhecimento científico ${ }^{1}$ e o senso comum é conflituosa desde que o primeiro se tornou sinônimo de verdade absoluta enquanto o segundo, estabelecido no patamar de sabedoria popular, foi desvalorizado e associado a falta de conhecimento acadêmico. Esse embate também pode ser percebido por um viés político e econômico ao observamos o movimento colonizador. Com o progresso tecnológico de algumas nações, o saber científico passou a se instituir como aquele ligado à evolução enquanto o senso comum foi atribuído ao saber dos países em "atraso" (Santos, 2010).

O pensamento do sociólogo português Boaventura de Sousa Santos (1995; 2006; 2010) sobre a ciência é construído a partir deste prisma histórico-social. $\mathrm{O}$ pesquisador enxerga na dominação colonialista uma igual sobreposição epistemológica que relega os saberes locais a posições subalternas e, muitas vezes, acaba por suprimi-los.

No combate a essa dominação epistemológica, Santos (1995) questiona os paradigmas que sustentam a ciência moderna enquanto instituição legitimadora da verdade, aponta os prejuízos que sua manutenção traz às sociedades que vivem sob a hegemonia capitalista vigente e sugere uma nova epistemologia que se aproxime do saber popular e que promova uma ciência que gere resultados positivos para todas as nações.

Entretanto, esse discurso se encontra enraizado de tal maneira no mundo atual que, como o próprio pesquisador reconhece (Santos, 2010), ele toma forma dentro das sociedades nas quais ele foi imposto, passando, às vezes, despercebido por aqueles que o pronunciam.

Neste trabalho, objetivamos encontrar traços dessa relação conflituosa entre o conhecimento científico e o senso comum, utilizando como parâmetros

1. Entende-se por conhecimento científico o saber produzido dentro de instituições de pesquisa e que estejam de acordo com preceitos teóricos e metodológicos do campo científico. 
A hegemonia científica e o senso comum na internet: uma análise segundo a Epistemologia do Sul de Boaventura de Sousa Santos

teóricos algumas das obras de Boaventura de Sousa Santos. Para isso, iremos analisar os discursos contidos em um debate entre um paisagista, assumidamente um prático empirista, e um acadêmico graduado em Biologia e com mestrado e doutorado em Liquenologia. Ambos debateram acerca da relação entre liquens e árvores em um site de conteúdo sobre jardinagem e paisagismo. Também verificaremos como o debate entre ambos afetam os demais frequentadores da referida página.

\section{Desenvolvimento}

Rubem Alves (1981) disse no início da década de 1980 que a ciência era como uma hipertrofia do senso comum, uma especialização de um saber. $\mathrm{O}$ autor ressaltava, ainda, que a imagem do cientista está ligada diretamente a uma posição de autoridade que este havia conseguido dentro da sociedade. Essa especialização e, principalmente, essa autoridade são reflexos do desenvolvimento do pensamento científico moderno, o qual tem suas bases no Iluminismo e que vê no conhecimento científico o verdadeiro saber em detrimento do senso comum. E isto se mantém nestes mesmos moldes até os dias atuais, como o próprio Alves (1981) exemplifica, quando não perguntamos a um médico acerca da eficácia de determinado medicamento que fora produzido por cientistas em seus laboratórios. Entretanto, a utilização desses conceitos vem sendo questionada há algum tempo, pois o indivíduo cartesiano, projetor desse ideário, deixa de ter a centralidade e unidade que lhe era atribuída (Hall, 2006).

Um desses questionamentos envolve diretamente as mudanças políticoeconômicas que ocorreram no mundo durante do século XX e que afetam diretamente a construção epistemológica. Com novos centros de poder econômico fora do eixo Europa - América do Norte, com o avanço da tecnologia informacional e um crescente número de mobilizações sociais, ocorreu também um descentramento do pensamento científico.

De acordo com Santos (2010) a manutenção do pensamento científico moderno, ao qual ele classifica como dominante, percorre o mesmo caminho que o da dominação sociopolítica. Sua ascensão e manutenção estariam ligadas diretamente ao movimento colonizador que ocorreu no mundo durante os últimos séculos, com predominância de alguns países europeus e, mais recen- 
temente, dos Estados Unidos, e que resultou na atual divisão geopolítica. No seu entendimento,

"o colonialismo, para além de todas as dominações por que é conhecido, foi também uma dominação epistemológica, uma relação extremamente desigual entre saberes que conduziu à supressão de muitas formas de saber próprias de povos e nações colonizados, relegando muitos outros saberes para um espaço de subalternidade" (Santos, 2010, p. 11).

O pensamento científico moderno teve início e se desenvolveu ancorandose nas chamadas ciências naturais, que tinham entre seus paradigmas a separação entre sujeito e objeto e entre natureza e sociedade, a diminuição da complexidade a leis que pudessem ser provadas matematicamente e o reconhecimento do saber científico como verdadeiro em detrimento do senso comum e das humanidades. Somente no século XIX, os estudos sociais passaram a utilizar dos métodos e técnicas das ciências naturais e, com isso, passaram a compartilhar o status de ciência. E, é a partir do estabelecimento de relações entre as duas ciências, que se constitui um modelo global de racionalidade científica (Santos, 1995, p. 10).

De acordo com Santos (Idem, p.11) essa racionalidade científica instituiu um modelo totalitário o qual nega os conhecimentos que não atendem aos seus princípios epistemológicos e metodológicos. Os cientistas modernos atraíram para si a autoridade sobre a construção do pensamento racional e científico por meio da afirmação dos seus conhecimentos sob seus contemporâneos e, com isso, estabeleceram seu lugar na sociedade (Ibidem).

Entretanto, como dito anteriormente, o pensamento científico moderno, embasado nos preceitos e modelos definidos pelas ciências naturais, começa a enfrentar uma crise já no início do século XX, tanto pelas novas condições sociais que passam a existir quanto pelo avanço tecnológico resultante destes próprios estudos científicos. Santos (1995) utiliza quatro avanços das pesquisas nas ciências naturais para validar seu pensamento.

O primeiro passo para o entendimento dessa crise é identificar que o próprio conhecimento propiciado pelo paradigma científico moderno permitiu reconhecer que nele há limites e que os pilares aos quais eles são estabelecidos são frágeis. Para isso o autor utiliza como exemplo a teoria da relatividade e simultaneidade, de Einstein, que se opõe à teoria do tempo e espaço absolutos de Newton. O segundo ponto se refere à relação entre pesquisador e objeto pesquisado, a qual a microfísica de Heisenberg e Bohr mostrou que não é pos- 
A hegemonia científica e o senso comum na internet: uma análise segundo a Epistemologia do Sul de Boaventura de Sousa Santos

sível o primeiro observar o segundo sem qualquer tipo de modificação neste. O teorema da incompletude de Gödel, que contesta o rigor da matemática, acaba por questionar também o rigor das formalizações científicas, uma vez que estas tinham como base a matemática. Por fim, Santos (1995, p. 27) vê na teoria das estruturas dissipativas de Prigogine o quarto ponto de crise do pensamento científico moderno, uma vez que ela se contrapõe ao princípio da entropia das matérias fornecido pela física clássica.

Além desses pontos, Santos (1995, p.30) lembra que os pensamentos que originaram essa crise partiram de cientistas que buscaram uma compreensão filosófica para além dos seus conhecimentos físico-químico-biológicos, a fim de problematizarem suas próprias práticas científicas. E, como dito há dois parágrafos, as condições sociais e culturais passaram a ter significância e a ocupar um papel de destaque na reflexão epistemológica, o que nos remete ao domínio científico de países europeus, dos Estados Unidos, e do leste asiático. Neste sentido, tais países passaram a investir na industrialização da ciência, o que "acarretou o compromisso desta com os centros de poder econômico, social e político, os quais passaram a ter papel decisivo na definição das prioridades científicas" (Santos, 1995, p. 34). Com isso, a comunidade científica foi dividida e as relações entre os cientistas tornaram-se autoritárias e desiguais, o que levou a uma "proletarização no interior dos laboratórios e centros de investigação" (Idem, p. 35).

Pelo ponto de vista social, como cientista social que é, Santos (2006) enxerga na busca pela manutenção do pensamento científico moderno uma similaridade com o movimento político-econômico empreendido pelo capitalismo. Para ele, o colonialismo deixou suas marcas epistemológicas que não foram apagadas com o pós-modernismo. Aliás, o termo pós-modernismo, ligado diretamente ao momento em que vivemos e marcado por mudanças rápidas e constantes tanto do sujeito quanto das instituições sociais (Hall, 2006), é adotado por Santos em duas situações. Primeiro, em sua obra Um Discurso Sobre as Ciências (1995), publicada originalmente em 1985, na qual o autor o utiliza para definir um momento subsequente ao da ciência moderna em que um novo paradigma científico ${ }^{2}$ seria aplicado. Mais recentemente, em 2006, no livro $A$ Gramática do Tempo (2006), o conceito é ampliado para um viés social e po-

2. O paradigma de um conhecimento prudente para uma vida decente, o qual iremos abordar mais adiante. 
lítico e o termo vai buscar sua significância na crítica à modernidade ocidental de forma a compará-lo a um estágio pós-colonialista, onde somente os países do Atlântico Norte poderiam desfrutar dessa condição, embora que, para isso, ainda haja sofrimento humano nos países do Sul. Santos (2006, p. 27) propõe então uma "pós-modernidade de oposição" que combata a opressão social imposta pela pós-modernidade dos países dominantes.

Por outro lado, mesmo que o pensamento científico moderno busque se manter como dominante, sustentado por países de maior poder econômico e suas políticas de produção científica, Santos (2007, p. 25) irá defini-lo como indolente, dado ao seu posicionamento estanque em não se abrir para outros saberes. Como consequência dessa letargia, segundo Santos, haveria um desperdício de energia produtiva, pois se deixa de considerar que muitas coisas significativas para a ciência ocorrem no presente porque se vislumbra um futuro o qual os cientistas já conhecem: o progresso. Isso resultaria no que ele classifica como Sociologia das Ausências, que tenta "mostrar que o que não existe é produzido ativamente como não existente, como uma alternativa não crível, como uma alternativa descartável, invisível à realidade hegemônica do mundo" (Santos, 2007, p. 28-29).

Santos (2007) encara a construção das Ausências tal qual um modelo de monoculturas, pois, metaforicamente, elas apenas iriam extrair aquilo que o meio-ambiente pode oferecer sem que haja um trabalho de preservação. Há cinco monoculturas que contribuem para a manutenção das Ausências: monocultura do saber e do rigor, na qual o saber científico é o único que tem validade e o rigor metodológico para definir aquilo que é crível; monocultura do tempo linear, na qual persiste a ideia de uma linearidade histórica e que os países desenvolvidos estão à frente dos demais; monocultura da naturalização das diferenças, que encara diferenças étnicas, raciais, de classe social, de gênero como diferenças e não como igualdade, por meio da hierarquização e inferiorização; monocultura da escala dominante, na qual a racionalidade dominante é a do universalismo e da globalização, no sentido de que ambos desacreditam as realidades locais em favor dos pensamentos globais e universais; por último, a monocultura do produtivismo capitalista, na qual o ciclo da natureza e o trabalho humano são enquadrados dentro de uma lógica produtivista que descarta todo o restante que compõe o ser humano e o meio ambiente. 
A hegemonia científica e o senso comum na internet: uma análise segundo a Epistemologia do Sul de Boaventura de Sousa Santos

Todos estes aspectos que envolvem o pensamento científico moderno e sua relação com a manutenção de uma racionalidade que insiste em se manter dominante no atual formato social do mundo, compõem aquilo que o pensamento de Boaventura de Sousa Santos define como uma Epistemologia do Norte. Isso porque ela está diretamente ligada aos países que estão localizados geograficamente no Atlântico Norte, muito embora nem todos eles desfrutem do mesmo patamar socioeconômico e científico, como o próprio autor ressalta. Em contraposição à Epistemologia do Norte, Boaventura propõe uma Epistemologia do Sul, que, a princípio, tal qual à sua antagonista, não se restringe aos países do Sul geográfico, mas sim, a uma racionalidade emergente com vistas a um combate à supressão de saberes exercida pelo pensamento dominante. Essa divisão entre o pensamento científico ocidental e as epistemologias do Sul, Santos (2010) metaforicamente caracteriza como um abismo. De acordo com ele, essa linha estabelece que o conhecimento produzido no Sul seja considerado inexistente pelo Norte, pois a este só interessa o que é produzido por ele.

Dentro do contexto das Epistemologias do Sul, o primeiro ponto a se considerar é a própria relação epistemológica entre o pensamento científico moderno e o proposto por Santos (1995). Como dito acima, o pensamento científico moderno começou a entrar em uma crise a partir do momento em que os próprios cientistas passaram a buscar alternativas para romper com os limites que essa racionalidade impunha a si mesma. Para tal, Santos (Idem) vislumbra um paradigma emergente, o qual ele classifica como um "paradigma de um conhecimento prudente para uma vida decente" (ibidem, p. 37), pois se trata de uma construção epistemológica edificada em sociedade a partir da revolução promovida pela ciência. Ou seja, esse paradigma não deve ser apenas científico, mas também social.

O primeiro ponto para o estabelecimento desse paradigma é reconhecer que todo conhecimento científico-natural também é científico social. Para Santos (1995, p. 37) não há mais separação entre as ciências humanas e naturais, pois como ele próprio defende, a ciência atual é construída dentro de uma sociedade modificada por ela. Ora, mesmo as ciências naturais são concebidas hoje em dia em contextos sociais que não podem ser descartados. A dicotomia existente na separação entre estes dois tipos de ciências - naturais e sociais - deve ser rompida por ambos os lados. 
A segunda característica desse paradigma emergente busca eliminar as barreiras da disciplinarização dos saberes estabelecendo que todo conhecimento local é, também, total. Para Santos (1995, p. 46) o conhecimento disciplinar segrega, ao passo que estabelece fronteiras entre os saberes que não podem ser transpostas, e transforma o cientista em um especialista ignorante. Em contrapartida, o que o autor propõe é que essa fragmentação de conhecimentos seja posta de lado em prol de um saber total, separando não mais em disciplinas, mas em temas (Idem, p.47).

A quebra das fronteiras das disciplinas e a ampliação das áreas de conhecimento irá afetar diretamente o trabalho dos cientistas, que passarão a ter seus trabalhos mais personalizados, o que resultará no terceiro ponto da proposta de Boaventura: todo conhecimento é autoconhecimento (Santos, 1995, p. 50). Uma vez que o resultado do trabalho dos cientistas é tido como suas criações e que não se concebe mais uma separação entre sujeito e objeto de pesquisa, passa a existir a necessidade de reflexão sobre estes, pois "o objecto é a continuação do sujeito por outros meios" (Idem, p. 52).

Por fim, esses três pontos devem resultar na quarta característica do paradigma emergente, a qual todo conhecimento científico deve buscar se constituir como senso comum. Isso porque o paradigma científico emergente reconhece que, no senso comum, há virtudes que podem contribuir com o conhecimento científico, e vice-versa, para que ambas colaborem para uma melhor relação do ser humano com o mundo (Santos, 1995, p. 55-56).

Para se diminuir a indolência do pensamento científico moderno e romper o abismo que se estende entre Norte e Sul, deveríamos promover a realização desse paradigma estabelecendo um diálogo entre a ciência e os saberes por ela negados. Para isso, Boaventura propõe adotarmos uma Sociologia das Emergências (Santos, 2006) formada por ecologias que atuem contra as monoculturas que geram ausências.

A primeira é a ecologia de saberes, na qual, o importante "não é ver como o conhecimento representa o real, mas conhecer o que determinado conhecimento produz na realidade: a intervenção no real" (Idem, p. 33); com a ecologia da temporalidade devemos reconhecer que existem outros tempos que devem ser respeitados e que vão contribuir com a ampliação da nossa contemporaneidade; com a ecologia do reconhecimento podemos mitigar as diferenças até que restem apenas aquelas que não possam ser descartadas; na ecologia da transescala os projetos são articulados e os fenômenos analisados 
A hegemonia científica e o senso comum na internet: uma análise segundo a Epistemologia do Sul de Boaventura de Sousa Santos

em escalas locais, nacionais e globais; e com a ecologia das produtividades recuperaremos a valorização dos sistemas de produção alternativos e de projetos de economia popular e solidária.

Como dito ao longo desta comunicação, o grande objetivo a ser alcançado com o estabelecimento de um paradigma científico emergente é fazer com que o saber oriundo da ciência possa ser utilizado para uma vida melhor. Boaventura de Sousa Santos dentro da proposta da ecologia dos saberes (Santos, 2006, p. 46), nos diz que a universidade ainda é a grande produtora desse conhecimento e que seria ideal que elas realizassem uma extensão às avessas: ao invés de a universidade levar o conhecimento para a sociedade, esta trazer outros saberes para dentro da universidade. Entretanto, o que pode ser visto ainda nos dias atuais é um constante embate entre essas duas formas de saber, o senso comum e a ciência, cada uma tentando, a todo custo, desqualificar a outra por meio dos seus princípios. É o que iremos ver a seguir, com um exemplo retirado de um blog sobre jardinagem e paisagismo.

\section{Análise}

O blog Jardim das Ideias (www.jardimdasideias.com.br), se apresenta como um espaço para os amantes da jardinagem. Ele é mantido por uma empresa multinacional fabricante de máquinas e equipamentos para o trabalho florestal, agrícola e de jardinagem doméstica. Pelo copyright registrado no site, o Jardim das Ideias está no ar desde o ano de 2009 e oferece algumas funcionalidades para seus visitantes, como biblioteca de espécies, vídeos e concursos, entre outras. Eis a página inicial do blog ${ }^{3}$.

O post, objeto de nossa análise, foi publicado no dia 15 de setembro de 2009 e tem como tema o controle da expansão de liquens nas árvores. Até o dia 14 de janeiro de 2014, essa postagem recebeu um total de 91 comentários, 11 deles repetidos possivelmente por erro no seu sistema de inserção. Todos os comentários são nomeados, o que permitiu que realizássemos uma catalogação para identificar participações recorrentes. Com isso, constatamos a intervenção de 27 leitores, além do autor da informação e do especialista ${ }^{4}$.

3. Atualmente a página passou por mudanças estéticas e apresenta um layout diferente.

4. Iremos nomear o autor da informação apenas por "Autor", bem como o especialista será denominado por "Especialista", e os leitores "Leitor N" (onde N é determinado pela ordem cronológica de participação, indo de 1 a 27), pois, no nosso entendimento, tratá-los pelos seus 


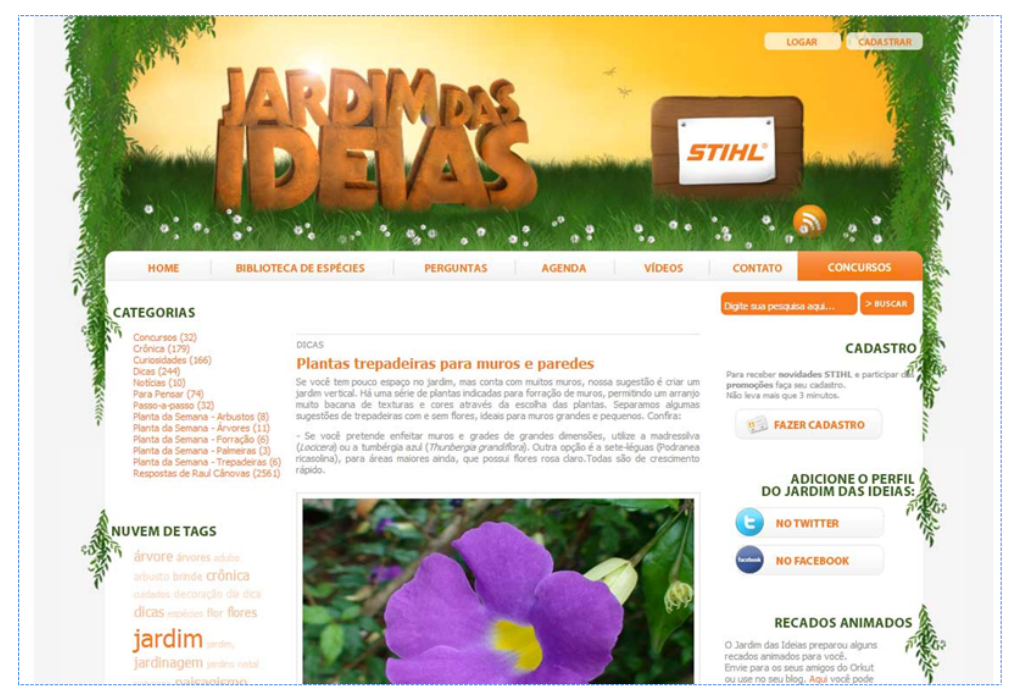

Figura 01. Homepage do blog Jardim das Ideias. Acesso em 10/02/2014.

\section{Segue a transcrição da informação veiculada ${ }^{5}$.}

Como controlar a expansão dos liquens nas árvores

Os liquens são organismos formados pela associação de um fungo com uma alga e aparecem colados em todo tipo de superfície: telhas, troncos, pedras, na terra e nas estátuas que estejam localizadas em locais sombreados pelas copas das árvores. Habitam dos trópicos ao ártico, onde não cresce praticamente nada.

Olhando através de um microscópio, um pedacinho de líquen, observamos duas plantas distintas: uma alga verde, ou levemente azulada e um fungo que tem filamentos rodeando a superfície dura da alga. Esta alga tem clorofila, por isso produz energia que recebe do sol e a divide com o fungo que fornece alimento mineral e abrigo. Esta parceria permite que o líquen viva milhares de anos.

nomes iria nos propiciar realizar e gerar juízos de valores sobre eles enquanto seres humanos e desviar o foco da nossa análise, que é a relação entre duas formas de conhecimento: o científico e o senso comum. A diferenciação entre a utilização de iniciais maiúsculas e minúsculas se dará em substituição dos nomes próprios de ambos para indicar que naquele ponto houve fala direcionada.

5. Disponível em www.jardimdasideias.com.br. Acesso em 10/01/2014. 
A hegemonia científica e o senso comum na internet: uma análise segundo a Epistemologia do Sul de Boaventura de Sousa Santos

São mais ou menos trinta mil variedades que vivem em todas as situações imagináveis: no deserto, na mata, na água doce, nas rochas à beira mar, e para alimentar-se retiram nutrientes de qualquer lugar, inclusive do vento.

Às vezes são um tanto abusados e cobrem quase que totalmente os troncos de arbustos e árvores. Nesse caso, para evitar a asfixia da planta , é aconselhável controlar sua expansão limpando o tronco e os galhos com uma escova dura, de nylon ou de arame ou ate com uma luva áspera de carneiro. Quando as infestações tomaram conta de uma superfície maior da árvore, pode-se passar pasta bordalesa na região com uma brocha. (Grifo nosso).

Na informação o autor descreve um pouco sobre o que são os liquens, onde e como eles vivem. Entretanto, ao final ele expõe que a cobertura excessiva desse microrganismo em um tronco de árvore pode levar à asfixia da mesma. Esse trecho, destacado no texto acima, é o qual iremos nos concentrar.

O diálogo por meio dos comentários teve início em outubro do mesmo ano. Entretanto, a primeira participação que questionou a informação veiculada pelo autor foi publicada no mês de janeiro de 2010. Nele, a Leitora 03 questiona "Como um líquen asfixia uma árvore??". A utilização de dois pontos de interrogação denota a uma pergunta retórica por parte dela. No entanto, a resposta do autor se restringe a reescrever o trecho o qual destacamos acima, sem qualquer explicação de "como" isso ocorre.

A primeira participação do Especialista ocorre no mês de agosto desse mesmo ano. Nela, ele questiona o conhecimento do autor acerca daquilo que ele informa por meio de explicações sobre a fixação dos liquens nas árvores e dizendo que não há a necessidade de qualquer tratamento para combatê-los. Poucos dias depois, eis a resposta do autor:

Você tem razão (pelo menos em parte) Especialista;

Os liquens são epífitos que não procuram o alimento de seus hospedeiros, não tendo qualquer relação com as parasitas. Entretanto, e sempre há um, entretanto, não apenas as parasitas comprometem o desenvolvimento das espécies lenhosas. Você já viu uma palmeira-acuri (Attalea phalerata) sendo abraçada até a morte por uma figueira-mata-pau (Ficus guaranitica), no Pantanal Mato-grossense? Percebeu o avanço avassalador de uma trepadeira conhecida como coração-de-estudante (Thunbergia grandiflora) em cima de um ipê-amarelo-cascudo (Tabebuia chrysotricha) que tenta em vão soltar suas folhas em setembro e não consegue 
porque essa planta o afogou por completo? Soube da invasão do cajepute (Melaleuca quinquenerva) na Florida, USA, massacrando a flora nativa desse bioma? O que acha desses exemplos onde alguma coisa escapa ao controle e destrói outra forma de vida vegetal?

Pois bem meu caro Especialista, a mesma coisa acontece quando o líquen-prateado (Parmelia carperata) se reproduz de modo continuado, graças à ação do vento, tomando os troncos e os ramos das árvores que não conseguem vegetar e entram em uma fase senescente, porque as brotações não podem competir com essas formas de vida. As árvores morrem, literalmente, asfixiadas. Isto foi constatado por mim na cidade de Suzano-SP, onde vi morrer uma alameda de tulipeiras (Spathodea nilotica) totalmente cobertas por esse líquen. Nessa região é comum ver outras espécies sofrerem com a presença de liquens: azaléias e outros arbustos definham por causa deles.

A calda bordalesa não é um procedimento agressivo é, apenas uma forma de controlar a expansão do líquen, como foi referido na minha matéria. Dou também parte de razão a você quando diz que desconheço o assunto; realmente não sou liquenólogo, sou apenas um paisagista que convive com o mundo vegetal há mais de meio século e isto me permite contemplar a paisagem de um modo menos pontual, desde um prisma ecosófico, onde procuro aproximar a ecologia ao pensamento abstrato dos homens que procuram algo além do pensamento cartesiano, que nos impede de sentir, obrigando-nos a racionalizar de forma cética.

Mas, enfim Especialista, agradeço suas colocações e espero que algum dia possa considerar-me seu colega.

Abraços,

No primeiro parágrafo do comentário-resposta, o autor utiliza dos nomes científicos de algumas plantas para expor seu conhecimento sobre o assunto, em resposta à desqualificação do comentário anterior. Em seguida, o autor explica o "como" solicitado no comentário da outra leitora, e justifica a ocorrência do fato por meio de um exemplo por ele acompanhado. Já no terceiro parágrafo, ele expõe sua atividade como paisagista com vasta experiência ("há mais de meio século") e utiliza isso para confrontar o conhecimento acadêmico, nesse período representado pelo "pensamento cartesiano" que obriga os cientistas a pensarem de forma cética.

Neste ponto há o primeiro embate entre o discurso científico e o senso comum. Em sua resposta, mais especificamente sobre o caso das tulipeiras mortas na cidade de Suzano (SP) ele apresenta como único argumento o excesso 
de liquens nas árvores, porém sem considerar a existência de outros fatores que pudessem ter influência sobre o fato, como, por exemplo, deficiência de adubação do solo.

Em resposta ao autor, o especialista afirma que

Prezado Autor

O número de coisas absurdas que você mencionou é muito problemático. Eu sou um dos poucos especialistas em liquens do Brasil, tenho Mestrado e Doutorado em liquenologia (trabalho na Secretaria do Meio Ambiente do Estado de SP, no Instituto de Botânica), conheço Parmelia caperata muito bem assim como outras 2514 espécies até o momento, e posso garantir que a cobertura de um trono por liquens, seja ela total ou parcial, NADA tem a ver com a morte de um vegetal. Nenhuma de suas estruturas penetra na casca mais que o suficiente para se fixar sobre ela, isso quando penetra, e toda a nutrição vêm da relação simbiótica e do ambiente, tal como a poeira mineral que percola da copa ao tronco quando chove ou é trazida pelo vento.

EU posso GARANTIR que nada do que você disse é verdade. É uma alegação sua baseada numa observação e conclusão sem NENHUM fundamento científico! "a, os liquens cobrem as plantas, então por isso elas estão morrendo!"

Isso é simplesmente ABSURDO!!!pelo amor de Deus, não divulgue isso a leigos! Se você não conhece a biologia de um organismo, não deve tirar conclusões precipitadas sobre elas.

Note que estou falando dos liquens, e não de outros grupos de fungos, como os que o senhor mencionou no primeiro parágrafo.

A propósito, o nome atual do liquen prateado que o senhor mencionou é Parmotrema caperatum, e dessa família constam atualmente mais de 2500 espécies. Tem idéia do nivel do seu desconhecimento? Num tronco de árvore isolado, eu já cheguei a identificar mais de 120 espécies de liquens. O recorde de que já ouvi falar é 187.

Eu até quero ajudar você, mas por favor, não divulgue algo sem antes consultar um especialista! Você faz idéia de quantos alunos nos procura todos os anos querendo fazer iniciação científica, mestrado ou doutorado com liquens como bioindicadores ou biomonitores?

Um abraço.

Neste comentário, o especialista busca reafirmar a posição do saber científico em detrimento ao senso comum. Ele utiliza seus títulos acadêmicos e 
expõe seu lugar de trabalho - em um centro de pesquisa - para conferir autoridade à sua fala. Ele ainda explica o modo de fixação de uma espécie em outra para contrapor o raciocínio do autor, o qual, segundo ele, não atende fundamentos científicos. Como o diálogo se estabelece por meio da escrita, o especialista utiliza algumas palavras em letras maiúsculas, um recurso comum no meio digital que remete a uma entonação forte da voz. No terceiro parágrafo, o especialista demonstra preocupação na divulgação de uma informação que não foi comprovada cientificamente para o público, o que reforça a sua ideia de institucionalização do saber para que este seja validado.

Para além dessas primeiras percepções visualizadas individualmente, o que podemos presenciar neste pequeno trecho do diálogo entre autor e especialista, e entre eles e nós, leitores, é um discurso no qual é possível notar o que Orlandi (2007, p. 39) define como o estabelecimento de uma relação de forças. Isso porque cada enunciador utiliza do seu lugar de fala - o primeiro como jardineiro experiente e o segundo como especialista titulado - para fazer provar seu ponto de vista. Neste sentido, de um lado notamos a afirmação da ciência enquanto única forma de conhecimento capaz de revelar a verdade das coisas, enquanto que de outro vemos uma corrente de pensamento que questiona essa posição.

Notamos ainda como a relação de sentidos é constituída. Como dito antes, a conversa entre os dois protagonistas remete ao embate entre conhecimento científico e senso comum, o que, no nosso ponto de vista, não significa uma disputa pessoal entre os dois indivíduos envolvidos, mas sim uma disputa simbólica, sócio-histórica e ideológica, que é responsável pelo sentido amplo ao qual este discurso foi produzido (Orlandi, 2007, p. 30). Nesse caso, também podemos observar a presença de um esquecimento ideológico (Idem, p. 35), pois cada enunciador retoma sentidos pré-existentes que lhes significam de acordo com seus posicionamentos na sociedade.

A busca em referências outras para legitimarem seus discursos perante o debatente - o autor em sua experiência de "mais de meio século" e o especialista em sua formação institucional - remete, ainda, à vontade de afirmarem seus discursos como verdadeiros (Foucault, 1999) e, por assim, adquirirem algum poder para ser exercido sobre o interlocutor. É claro que, no caso do especialista esse exercício da vontade de verdade vai ser mais latente, uma vez que a própria ciência, institucionalizada, tal como relata Foucault (Idem, 
A hegemonia científica e o senso comum na internet: uma análise segundo a Epistemologia do Sul de Boaventura de Sousa Santos

p. 17), tem inúmeros mecanismos para apoiar sua posição, como livros, laboratórios, congressos, etc.

Tais defesas de locais de fala fazem com que, ao longo do debate entre autor e especialista, os leitores tomem posições por um ou por outro ${ }^{6}$. O que se vê por meio das falas dos leitores é a mesma construção de sentido dos protagonistas. Alguns dos que defendem o autor o fazem por este ter um passado prático que os remetem a um conhecimento real, ao mesmo tempo em que subestimam o conhecimento acadêmico. A exemplo da Leitora 08, que diz: "Eu prefiro acreditar no Sr. Autor e salvar minhas plantas, do que acreditar no Dr. Especialista e ficar vendo minhas plantas morrerem". Por outro lado, os que defendem o local de fala do especialista o fazem sustentando o conhecimento acadêmico, como este trecho do comentário da Leitora 10, descrito abaixo:

“[...] Vou mandar um recado a você e as pessoas que acreditam em você, procurem estudar, porque tudo o que esta escrito neste artigo nao passa de baboseira. Liquens não fazem mal a planta, FUNGOS sozinhos é que fazem, e ALGUMAS espécies de fungos.. como orelha de pau, ai sim vocês deverão se preucupar com suas plantas. OS LIQUENS SAO BIOINDICADORES DE POLUIÇÃO, ELES NOS AJUDAM A VERIFICAR A QUALIDADE DO AMBIENTE OK?! [...]"

Em dado momento, o autor deixa de responder aos comentários dos leitores e sua voz é substituída pela da instituição administradora do site que, em suas respostas conta com a "colaboração" de um engenheiro agrônomo. Em sua primeira participação efetiva, para sanar as dúvidas da leitora 16, a voz institucional passa a concordar com o especialista - no que se refere aos liquens não serem problemas para as árvores - e a recomendar aos leitores que não utilizem quaisquer métodos para controlarem os liquens. Mesmo assim, até a data de produção deste artigo, o texto original não havia sido modificado.

\section{Considerações}

Este embate entre o autor paisagista, de construção prática, e o especialista, com seu saber comprovado institucionalmente pela academia, figura apenas como exemplo das divergências entre o conhecimento oriundo do saber científico e o advindo do senso comum, abordadas pelo pensamento de

6. Devido ao espaço deste artigo não será possível detalhar as participações dos leitores, o que engrandeceria essa comunicação. 
Boaventura de Sousa Santos. Tal qual o movimento colonialista, o conhecimento científico abarca em um território e se impõe através dos seus paradigmas e da sua trajetória sócio-histórica.

Vemos de forma nítida o exercício de uma monocultura do saber e do rigor ligada diretamente à manutenção de uma epistemologia dominante, que se solidifica a partir do momento em que o ator empirista é substituído pelo ator institucional, bem como da vontade de verdade, ao passo que este utiliza um discurso similar ao do especialista. Com isso, percebemos também que há uma busca por dominação político-social para além da epistemológica, uma vez que, ao institucionalizar a palavra, os administradores objetivam ter credibilidade junto aos dois públicos - aos leitores prestando auxílio em seus questionamentos e embasando suas respostas com a voz de um 'engenheiro', profissão que transmite maior credibilidade em assuntos "técnicos" em nossa sociedade; e ao público especialista, que terá seu discurso verificado como verdadeiro por um representante do meio acadêmico.

Entretanto, a institucionalização do conhecimento acaba por diminuir o diálogo com os outros saberes que poderiam emergir de um diálogo produtivo entre a ciência e o senso comum, uma vez que muitos conhecimentos não foram catalogados. Essa supressão do saber do senso comum acaba por reforçar a ideia de existência de um abismo que o separa do conhecimento científico.

Do outro lado, porém, observamos que a construção de um espaço para discussão de assuntos do cotidiano, neste caso relativos à natureza, é um exemplo de um caminho que pode ser utilizado para se promover o paradigma emergente (Santos, 1995) em todas as áreas do conhecimento. Inserir temas de ambos os lados, da ciência e do senso comum, para debates e apreciações pode ser positivo tanto para a academia, que terá mais um caminho para conversar com a sociedade, quanto para o povo, que pode dialogar com outros saberes e trocar experiências. Entretanto, essa conversação deve ser realizada tendo em vista que os objetivos não são provar-se frente ao outro, mas colaborar para uma construção de um saber que torne a vida mais decente.

\section{Referências}

Alves, R. (1981). Filosofia da ciência: introdução ao jogo e suas regras. São Paulo: Brasiliense.

Foucault, M. (1999). A ordem do discurso. São Paulo: Loyola. 
A hegemonia científica e o senso comum na internet: uma análise segundo a Epistemologia do Sul de Boaventura de Sousa Santos

Hall, S. (2006). Identidade cultural na pós-modernidade. Rio de Janeiro: DP\&A.

Orlandi, E.P. (2012). Análise de discurso: princípios \& procedimentos. Campinas: Ponte.

Santos, B.S. (1995). Um discurso sobre as ciências. Lisboa: Afrontamento.

Santos, B.S. (2006). A gramática do tempo: para uma nova cultura política. São Paulo: Cortez.

Santos, B.S. (2007). Renovar a teoria crítica e reinventar a emancipação social. São Paulo: Boitempo.

Santos, B.S. (2010). Para além do pensamento abissal: das linhas globais a uma ecologia de saberes. In B.S. Santos \& M.P. Meneses. (Orgs). Epistemologias do Sul. São Paulo: Cortez. 